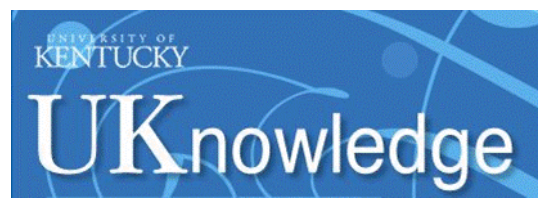

University of Kentucky

UKnowledge

$6-2-2016$

\title{
Aqueous Photochemistry of Glyoxylic Acid
}

Alexis J. Eugene

University of Kentucky, alexis.eugene@uky.edu

Sha-Sha Xia

University of Kentucky

Marcelo I. Guzman

University of Kentucky, marcelo.guzman@uky.edu

Follow this and additional works at: https://uknowledge.uky.edu/chemistry_facpub

Part of the Analytical Chemistry Commons, Atmospheric Sciences Commons, Environmental

Chemistry Commons, Environmental Engineering Commons, Organic Chemistry Commons, and the

Physical Chemistry Commons

Right click to open a feedback form in a new tab to let us know how this document benefits you.

\section{Repository Citation}

Eugene, Alexis J.; Xia, Sha-Sha; and Guzman, Marcelo I., "Aqueous Photochemistry of Glyoxylic Acid" (2016). Chemistry Faculty Publications. 66.

https://uknowledge.uky.edu/chemistry_facpub/66

This Article is brought to you for free and open access by the Chemistry at UKnowledge. It has been accepted for inclusion in Chemistry Faculty Publications by an authorized administrator of UKnowledge. For more information, please contact UKnowledge@lsv.uky.edu. 


\section{Aqueous Photochemistry of Glyoxylic Acid}

\section{Digital Object Identifier (DOI)}

http://dx.doi.org/10.1021/acs.jpca.6b00225

\section{Notes/Citation Information}

Published in The Journal of Physical Chemistry A, v. 120, issue 21, p. 3817-3826.

Copyright @ 2016 American Chemical Society

ACS AuthorChoice - This is an open access article published under an ACS AuthorChoice License, which permits copying and redistribution of the article or any adaptations for non-commercial purposes. 


\title{
Aqueous Photochemistry of Glyoxylic Acid
}

\author{
Alexis J. Eugene, Sha-Sha Xia, and Marcelo I. Guzman* \\ Department of Chemistry, University of Kentucky, Lexington, Kentucky 40506, United States
}

Supporting Information

ABSTRACT: Aerosols affect climate change, the energy balance of the atmosphere, and public health due to their variable chemical composition, size, and shape. While the formation of secondary organic aerosols (SOA) from gas phase precursors is relatively well understood, studying aqueous chemical reactions contributing to the total SOA budget is the current focus of major attention. Field measurements have revealed that mono-, di-, and oxo-carboxylic acids are abundant species present in SOA and atmospheric waters. This work explores the fate of one of these 2-oxocarboxylic acids, glyoxylic acid, which can photogenerate reactive species under solar irradiation. Additionally, the dark thermal aging of photoproducts is studied by UV-visible and fluorescence spectroscopies to reveal that the optical properties are altered by the glyoxal produced. The optical properties display periodicity in the time domain of the UV-visible spectrum of chromophores with absorption enhancement (thermochromism) or loss (photobleaching) during nighttime and daytime cycles, respectively. During irradiation, excited state glyoxylic acid can undergo $\alpha$ -

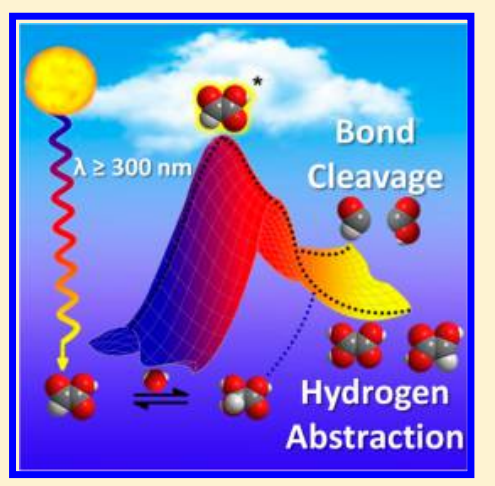
cleavage or participate in hydrogen abstractions. The use of ${ }^{13} \mathrm{C}$ nuclear magnetic resonance spectroscopy (NMR) analysis shows that glyoxal is an important intermediate produced during direct photolysis. Glyoxal quickly reaches a quasi-steady state as confirmed by UHPLC-MS analysis of its corresponding (E) and (Z) 2,4-dinitrophenylhydrazones. The homolytic cleavage of glyoxylic acid is proposed as a fundamental step for the production of glyoxal. Both carbon oxides, $\mathrm{CO}_{2}(\mathrm{~g})$ and $\mathrm{CO}(\mathrm{g})$ evolving to the gas-phase, are quantified by FTIR spectroscopy. Finally, formic acid, oxalic acid, and tartaric acid photoproducts are identified by ion chromatography (IC) with conductivity and electrospray (ESI) mass spectrometry (MS) detection and ${ }^{1} \mathrm{H}$ NMR spectroscopy. A reaction mechanism is proposed based on all experimental observations.

\section{INTRODUCTION}

Recently, aqueous-phase chemistry was suggested to contribute to the total SOA budget, ${ }^{1,2}$ for example, a simple 2oxocarboxylic acid, such as pyruvic acid, can initiate the formation of oligomers in the aqueous phase and even in ice. ${ }^{3-5}$ Simultaneously, inorganic electrolytes, such as ammonium and sulfate, are now known to play a role during dark processes. ${ }^{6,7}$ Among all the species found in aqueous SOAs (aqSOA), 2oxocarboxylic acids, such as glyoxylic acid (GA, $\left.\mathrm{p} K_{\mathrm{a}}=3.13\right){ }^{8}$ are widely present in different environments. Photo-oxidative processing of isoprene $e^{9-11}$ and aromatics ${ }^{12-16}$ produce first generation products such as methylglyoxal, glyoxal, phenol, catechol, and benzaldehyde. In more detail, glyoxylic acid can be directly produced from $\mathrm{HO}^{\bullet}$ attack on glyoxal, glycolic acid or hydroperoxy acetic acid, ${ }^{17}$ and during the oxidation of oxygenated aromatic species. ${ }^{14,15}$ Glyoxylic acid is the most abundant 2-oxocarboxylic acid present in organic aerosols in diverse environments. ${ }^{18-20}$ The annual net production of glyoxylic acid in atmospheric waters totals $2.95( \pm 0.89) \times 10^{10}$ mol year $^{-1} \equiv 0.71( \pm 0.21)$ TgC year ${ }^{-1},{ }^{21}$ with up to $85 \%$ concentrated in the particle phase. ${ }^{22}$ The small contribution of the aldehyde form of glyoxylic acid to its total speciation in water provides a tail for absorbing actinic radiation, allowing photoreactions to occur. Interestingly, the direct photoreaction of glyoxylic acid in water has remained previously unexplored and is investigated herein.
In this research, the identification of missing mechanisms of SOA production is investigated by monitoring the sunlight photolysis of aqueous glyoxylic acid, which is followed by thermal reactions during dark periods. The work (1) explores how atmospheric chemical reactions of interest proceed in atmospheric water mimics, affecting the optical properties of model aqSOAs; (2) identifies the reaction products by ion chromatography with dual conductivity and electrospray (ESI) mass spectrometric detection (IC-MS), ultrahigh pressure liquid chromatography mass spectrometry (UHPLC-MS) of derivatized samples with 2,4-dinitrophenylhydrazine (DNPH), and ${ }^{13} \mathrm{C}$ nuclear magnetic resonance spectroscopy (NMR); and (3) reports the time series of products involved in the reaction mechanism. The research contrasts the importance of dicarbonyl intermediates affecting the optical properties of model aqSOAs during photochemical and thermal processes. On the basis of the information gathered, a mechanism that agrees with all experimental observations for the photoreaction of glyoxylic acid is presented.

\section{EXPERIMENTAL SECTION}

Preparation of Experiments and Controls. In a typical experiment, solutions of glyoxylic acid (Sigma-Aldrich, 52.1 wt

Received: January 9, 2016

Revised: $\quad$ May 10, 2016

Published: May 18, 2016 
$\%$ in $\mathrm{H}_{2} \mathrm{O}$ ) were prepared daily in water (Elga Purelab flex, 18.2 $\mathrm{M} \Omega \mathrm{cm}^{-1}$ ) at a concentration of ca. $250 \mathrm{mM}$. Additionally, experiments studied the effect of glyoxylic acid concentration covering the range 5-250 $\mathrm{mM}$ (Supporting Information). The solution of glyoxylic acid was doped with the most abundant inorganic electrolytes found in seawater as a precursor of sea spray: ${ }^{23}\left[\mathrm{Na}^{+}\right]=468 \mathrm{mM},\left[\mathrm{Cl}^{-}\right]=545 \mathrm{mM}$, and $\left[\mathrm{SO}_{4}{ }^{2-}\right]=$ $28.2 \mathrm{mM}$. Electrolytes were provided similarly as described before $^{24}$ from $\mathrm{NaCl}$ (Fisher, 99\%), $\mathrm{Na}_{2} \mathrm{SO}_{4}$ (Fisher, 99\%), and $\mathrm{HCl}(\mathrm{EMD}, 38 \%)$. The absence of $\mathrm{NH}_{4}^{+}$in the mixture allows for focusing the work on the effects caused by photoirradiation instead of reiterating the reported catalysis by ammonium ${ }^{25}$ that can lead to decarboxylation. ${ }^{3,4,7}$ After adjusting the $\mathrm{pH}$ of the solution of glyoxylic acid to 1.0 with $[\mathrm{HCl}]=2.0 \mathrm{M}, 180$ $\mathrm{mL}$ of the solution were transferred to a fused silica photoreactor (220 mL capacity) with a jacket for temperature control at $298 \mathrm{~K}$ (Thermo Scientific A25 circulating bath), magnetic stirring, and a septum for sampling gases. The sealed reactor underwent continuous sparging (unless indicated otherwise) with $100 \mathrm{~mL} \mathrm{~min}^{-1}$ air (Scott-Gross, UHP) starting $30 \mathrm{~min}$ before photolysis. Experiments were performed under 1 atm air and the conditions of ionic strength, temperatures, and photon flux are chosen to simulate those encountered by nascent sea spray aerosols mixing with pollution plumes at coastal regions.

Control experiments (Table S1) were designed to study the effect of inorganic electrolytes and $\left[\mathrm{O}_{2}(\mathrm{aq})\right]$ on the photoreaction of glyoxylic acid. Table $\mathrm{S} 1$ indicates which gas was used and if electrolytes were not present in the controls: Control A under $1 \mathrm{~atm} \mathrm{~N}_{2}$ (g) (Scott-Gross, UHP), control B under 1 atm $\mathrm{O}_{2}(\mathrm{~g})$ (Scott-Gross, UHP), control $\mathrm{C}$ without electrolytes, control D without electrolytes under $1 \mathrm{~atm} \mathrm{~N}_{2}(\mathrm{~g})$, and control $\mathrm{E}$ without electrolytes under 1 atm $\mathrm{O}_{2}(\mathrm{~g})$. From Henry's law $\left(K_{\mathrm{H}}=1.28 \times 10^{-3} \mathrm{M}\right.$ atm $^{-1}$ for $\mathrm{O}_{2}$ at $\left.298 \mathrm{~K}\right){ }^{26}$ $\left[\mathrm{O}_{2}(\mathrm{aq})\right]_{\text {latmair }}=0.26 \mathrm{mM}$ and $\left[\mathrm{O}_{2}(\mathrm{aq})\right]_{1 \mathrm{atmO}}=1.24 \mathrm{mM}$.

Photochemical Experiments and Thermal Treatment of Photolyzed Samples. The photochemical setup (Newport) employed was previously described. ${ }^{27,28}$ Briefly, it includes a $1 \mathrm{~kW}$ high-pressure $\mathrm{Xe}-\mathrm{Hg}$ lamp, a water filter to remove infrared radiation, and a cutoff filter for wavelength $\lambda \geq$ $305 \mathrm{~nm}$ to provide actinic radiation in the solar window. The incident light intensity, $I_{0}=3.892( \pm 0.001) \times 10^{-5}$ Einstein $\mathrm{L}^{-1}$ $\mathrm{s}^{-1}$, was quantified by chemical actinometry using the concerted photodecarboxylation of phenylglyoxylic acid at $\mathrm{pH} 1.0$. $^{29} \mathrm{~A}$ calibrated polarographic probe (081010MD) connected to a meter (both Thermo Scientific) was used to monitor dissolved oxygen $\left(\left[\mathrm{O}_{2}(\mathrm{aq})\right]\right)$ levels during irradiation. During the first stage of processing (stage $\mathrm{I}$ in Scheme 1), samples of the experiment and controls (Table S1) were irradiated for $8 \mathrm{~h}$, and $5 \mathrm{~mL}$ aliquots were withdrawn from the reactor at $0,0.5,1,2,3$, 4, 5, 6, 7, and $8 \mathrm{~h}$. A sample volume of $3.5 \mathrm{~mL}$ was transferred to a Suprasil cuvette (Starna Cells, $10 \mathrm{~mm}$ optical path length) to monitor its aging (stage II in Scheme 1) in the dark by UVvisible spectroscopy for $15 \mathrm{~h}$ at $298 \mathrm{~K}$, followed by $9 \mathrm{~h}$ at $323 \mathrm{~K}$. The remaining aliquot was frozen at $253 \mathrm{~K}$ and stored in the dark for later analyses by IC-MS, UHPLC-MS, and NMR spectroscopy. The remaining $130 \mathrm{~mL}$ of photolyzed from the original solution was stored in the dark for $24 \mathrm{~h}$ (stage II in Scheme 1) and then rephotolyzed (stage III in Scheme 1). Rephotolyzed samples underwent a second aging process in the dark, monitored by UV-visible spectroscopy (stage IV in Scheme 1).
Scheme 1. Representation of the Processing of Aqueous Glyoxylic Acid Solutions ${ }^{a}$

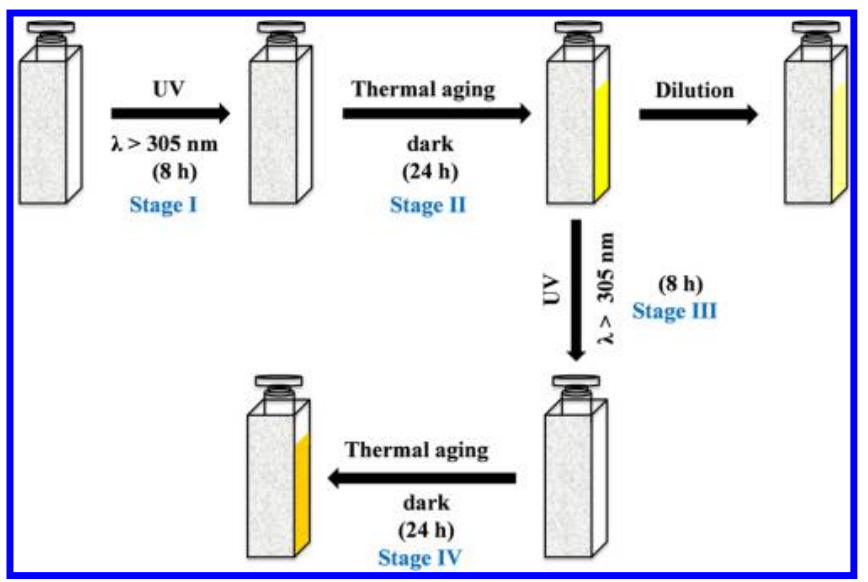

${ }^{a}$ Stages I and III are both $8 \mathrm{~h}$ photolysis periods. Stages II and IV sequentially refer to (dark) thermal aging during $15 \mathrm{~h}$ at $298 \mathrm{~K}$ followed by $9 \mathrm{~h}$ processing at $323 \mathrm{~K}$.

Analysis of Products. Samples were analyzed by (1) UVvisible spectroscopy (Evolution 220 spectrophotometer, Thermo Scientific) and fluorescence spectroscopy (FluoroMax-4 fluorimeter, Horiba Scientific); (2) IC-MS with a Dionex ICS-2000 instrument (IonPack AS11-HC, $2 \mathrm{~mm}$ analytical column) equipped with a conductivity detector and a mass spectrometer (MS) interfaced with an ESI probe (Thermo Scientific, MSQ Plus); ${ }^{27}$ (3) UHPLC-MS (Accela 1250 with MSQ Plus detector, Thermo Fisher Scientific) using a C18-selectivity column (Hypersil GOLD, $1.9 \mu \mathrm{m}, 50 \times 2.1$ $\mathrm{mm}$, Thermo Scientific) for separation of hydrazones from carbonyls derivatized with freshly prepared 2,4-dinitrophenylhydrazine (DNPH, Sigma-Aldrich, HPLC grade); ${ }^{30}$ (4) ${ }^{1} \mathrm{H}$ (using a WET suppression method) and ${ }^{13} \mathrm{C}$ NMR experiments (Varian $600 \mathrm{MHz}$ ) recorded at $298 \mathrm{~K}$ using $5 \mathrm{~mm}$ NMR tubes (Wilmad); and 5) Fourier transform infrared spectroscopy (FTIR) for evolving gases in a $2.4 \mathrm{~m}$ path length infrared gas cell with $\mathrm{ZnSe}$ windows (PIKE) mounted in an iZ10 FTIR module connected to an infrared microscope (Thermo Scientific Nicolet iN10). Data from all these methods is reported as the average of duplicate experiments with error bars corresponding to one standard deviation. Detailed information on all these experimental methods, instrumental parameters, samples and standards preparation, and quantification methods is given in the accompanying Supporting Information.

\section{RESULTS AND DISCUSSION}

Optical Properties. UV-visible spectroscopy is used to study the optical property changes of glyoxylic acid photolyzed under the conditions listed in Table S1. Figure 1 displays the UV-visible absorption spectra of $252.1 \mathrm{mM}$ glyoxylic acid before and after photolysis in the presence of electrolytes under 1 atm air (experiment in Table S1) for the four stages listed in Scheme 1. The reversible hydration of glyoxylic acid into dihydroxyacetic acid is shifted toward the hydrate form, as indicated by the large equilibrium constant $K_{\mathrm{Hyd}}=$ $\left[(\mathrm{OH})_{2} \mathrm{CH}-\mathrm{COOH}\right] /[\mathrm{O}=\mathrm{CH}-\mathrm{COOH}]=300$ (at 298 $\mathrm{K}) .^{31}$ Because the hydration equilibrium is shifted toward 2,2dihydroxyacetic acid, this species partitions to aerosols and clouds, and it is unlikely to return to the gas-phase. ${ }^{32}$ Although $K_{\mathrm{H}}$ is large for glyoxylic acid, the carbonyl group is still 


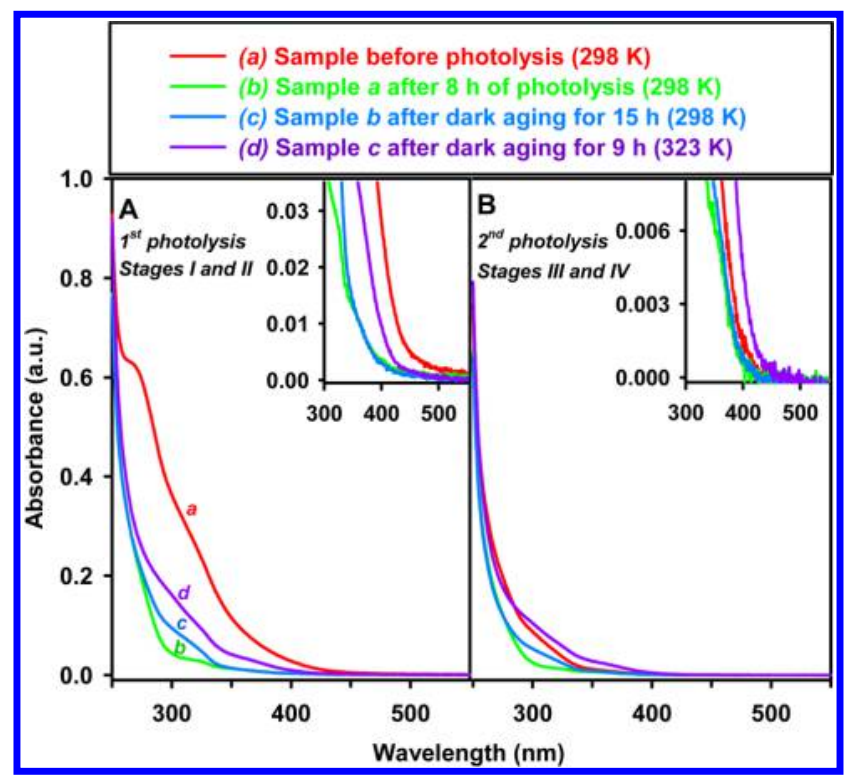

Figure 1. UV-visible absorption spectra during stages (A) I-II and (B) III-IV in Scheme 1. Spectrum (red line) before irradiation, after 8 $h$ photolysis (green line) for the end of stages I or III), followed by thermal aging during $15 \mathrm{~h}$ of at $298 \mathrm{~K}$ (blue line) and $9 \mathrm{~h}$ at $323 \mathrm{~K}$ (purple line), for the end of stages II or IV). Experimental conditions: Solution of [glyoxylic acid] $=252.1 \mathrm{mM},\left[\mathrm{Na}^{+}\right]=545.0 \mathrm{mM},\left[\mathrm{SO}_{4}{ }^{2-}\right]$ $=28.2 \mathrm{mM}$, and $\left[\mathrm{Cl}^{-}\right]=468.0 \mathrm{mM}$, at $\mathrm{pH}=1.0$ under 1 atm air.

observed in the spectrum before irradiation (red line in Figure 1A). Contrarily, other 2-oxocarboxylic acids such as pyruvic acid display a large fraction of carbonyl-form in equilibrium. ${ }^{33}$ The carbonyl absorption of glyoxylic acid at $\lambda=276 \mathrm{~nm}$ in Figure 1A comprises an absorbing tail that extends above $\lambda=$ $305 \mathrm{~nm}$.

After $8 \mathrm{~h}$ of irradiation, the green line in Figure 1A shows that for stage I photobleaching occurs. This change reflects the loss of the carbonyl functionality absorption band of the reagent and its associated tail in the UV. For the following $24 \mathrm{~h}$ of thermal aging in stage II, the blue and purple lines with increased absorbance resemble the effects of thermochromism in the sample. Figure 1B presents the results from a second irradiation period, such as a second daytime cycle (stage III) following the nighttime period for the last aged sample in Figure 1A. The mixture of products at time zero before the second photolysis is shown in red color in Figure 1B, which undergoes photobleaching (green line) producing a similar spectrum to that observed at the end of stage I in Figure 1A. Similarly, moderate thermochromism occurs in stage IV, during a second dark cycle, recovering a slightly higher absorption than after stage II.

The observed evolution of carbon species formed after stage I is related to the presence of coexistent aldehydes and gemdiols, alcohols, and carboxylic acids that are characterized below by several spectroscopic techniques. In the dark under mild atmospheric conditions, it is anticipated that glyoxal possesses the key aldehyde functional group that displays a continuum of absorption toward longer wavelengths. Interestingly, organic products absorbing in the $300-400 \mathrm{~nm}$ range were also observed during the thermal processing of solutions with [glyoxal] $=220 \mu \mathrm{M}-2.21 \mathrm{M}(\mathrm{pH} 4)$ in the presence of $\left(\mathrm{NH}_{4}\right)_{2} \mathrm{SO}_{4}$ or $\mathrm{NH}_{4} \mathrm{NO}_{3}{ }^{34}$ Because our experiment was purposely performed in the absence of ammonium ion, its catalytic effect in the self-condensation of aldehydes, ${ }^{25,34}$ its possible direct reaction with carbonyls resulting in heterocyclic products, ${ }^{35}$ as well as the possible formation of alkenes from alcohols, ${ }^{36}$ cannot be recalled to provide an explanation for the data in Figure 1. Beer's law was obeyed between 280 and 500 $\mathrm{nm}$ within the experimental accuracy. An example of the loss of linearity between 280 and $450 \mathrm{~nm}$ due to typical instrumental limitations is given in Figure S1.

Figure $2 \mathrm{~A}$ shows the normalized areas-to initial valuesintegrated under the UV-visible absorption spectra in the

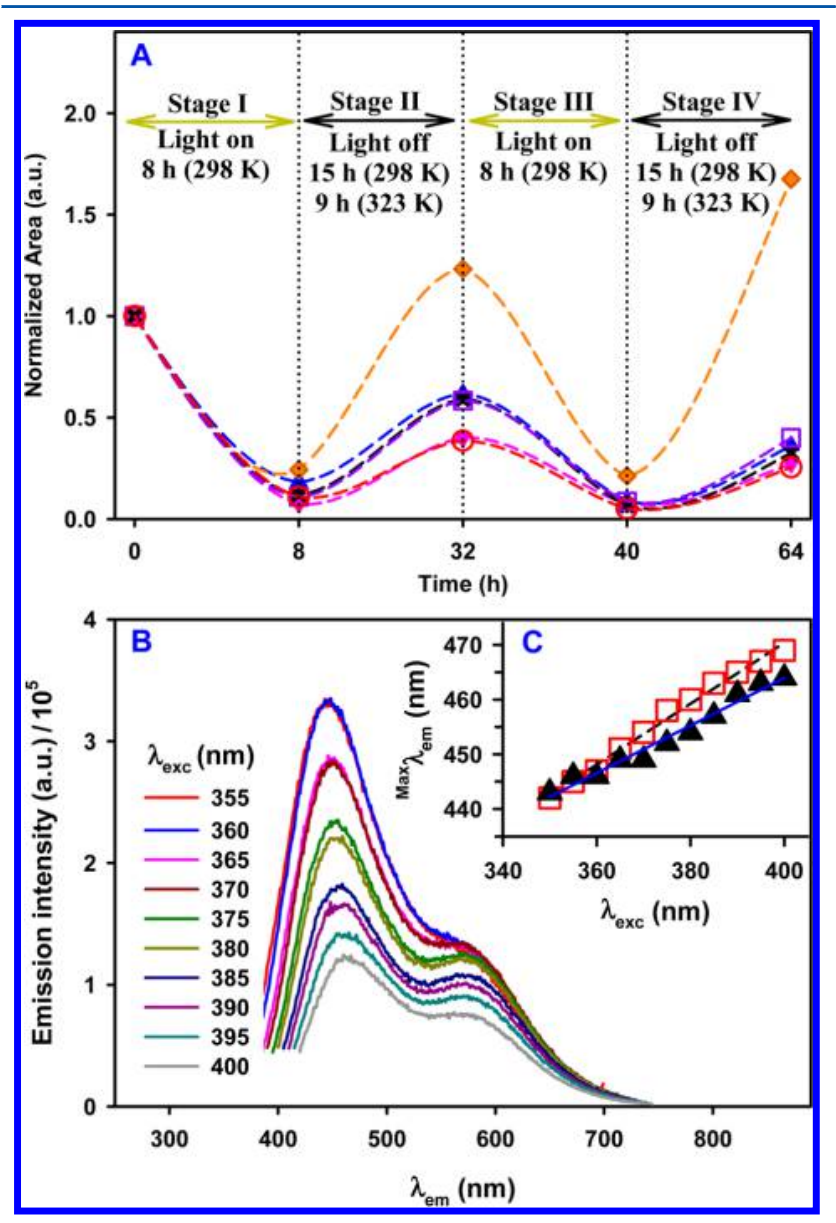

Figure 2. (A) Normalized area $(295 \leq \lambda \leq 500 \mathrm{~nm})$ under the UVvisible absorption spectra for (red $O$ ) an experiment, (blue $\mathbf{\Delta}$ ) control $A$ in $\mathrm{N}_{2},($ pink $\boldsymbol{\nabla})$ control $\mathrm{B}$ in $\mathrm{O}_{2},($ violet $\square$ ) control $\mathrm{C}$ without electrolytes, (orange control D without electrolytes in $\mathrm{N}_{2}$, and (black $X$ ) control $\mathrm{E}$ without electrolytes in $\mathrm{O}_{2}$. Experimental conditions defined in Figure 1. Dashed lines are to guide the eye and do not represent a model fit. (B) Fluorescence emission spectra under variable excitation wavelengths $\left(\lambda_{\text {exc }}\right)$ for the experiment in panel A at the end of Stage II. (C) Position of emission maxima $\left({ }^{\mathrm{Max}} \lambda_{\mathrm{em}}\right)$ for spectra in (black $\boldsymbol{\Delta}$ and blue solid line) panel B vs $\lambda_{\text {exc }}$ compared to (red $\square$ and dashed black line) a $24 \mathrm{~h}$ aged solution of [glyoxal] $=11.8 \mathrm{mM}$ with the same electrolytes.

wavelength interval $295 \leq \lambda \leq 500 \mathrm{~nm}$ during the four stages in Scheme 1 for the experiment and controls (Table S1). Control $\mathrm{F}$ in the absence of light remained stable over the four stages and is not included in Figure 2A. There is a large contrast between photobleaching stages I and III vs thermochromism stages II and IV. ${ }^{6}$ Each half cycle, simulating daytime vs nighttime periods, shows a dependence on the presence of inorganic electrolytes and $\left[\mathrm{O}_{2}(\mathrm{aq})\right]$. 
Although some dispersion is observed in the data set at the end of stage I in Figure 2A, thermochromism during stage II provides a better picture of how electrolytes and $\mathrm{O}_{2}(\mathrm{aq})$ act. Once stage II is complete, a comparison of the effect of $\left[\mathrm{O}_{2}(\mathrm{aq})\right]$ (experiment, control A, and control B in Table S1) in the presence of electrolytes, reveals that when $\mathrm{O}_{2}$ is present thermochromism is lower than in an inert atmosphere. The magnitude for the areas at the end of stage II follows the order $\mathrm{O}_{2}(\mathrm{~g}) \lesssim$ air $<N_{2}(\mathrm{~g}): 0.38 \lesssim 0.40<0.62$. A similar qualitative conclusion is valid for the subset of experiments in the absence of electrolytes (controls $\mathrm{C}, \mathrm{D}$, and $\mathrm{E}$ ) for the areas in air $\lesssim$ $\mathrm{O}_{2}(\mathrm{~g})<\mathrm{N}_{2}(\mathrm{~g}): 0.58 \lesssim 0.59<1.23$. The direct effect of electrolytes during thermochromism for stage II can be contrasted for the pair of subsets in air (experiment vs control C), in $\mathrm{N}_{2}(\mathrm{~g})$ (controls A vs $\mathrm{D}$ ), and in $\mathrm{O}_{2}(\mathrm{~g})$ (controls B vs $\mathrm{E}$ ). The results show that the lack of electrolytes in the sample similarly enhances thermochromism in air and $\mathrm{O}_{2}(\mathrm{~g})$, which increases further in $\mathrm{N}_{2}(\mathrm{~g})$, suggesting that the concentration of at least one species contributes to enhance the optical properties of the sample even in the absence of inorganic electrolytes in this simple system. After the second photobleaching and thermochromism periods in stages III and IV, the area of all samples start to merge but control D without electrolytes in $\mathrm{N}_{2}(\mathrm{~g})$ is the only one showing a different behavior. In general, the normalized areas follow a periodic function in the time domain with slightly decreasing amplitude for the different stages, an important observation to model the evolution of absorption properties of atmospheric brown carbon. $^{37}$

A recent chromatographic analysis of a nitrogen-containing brown carbon mixture concluded the red tail observed in the absorption spectrum could be explained as a linear combination of absorbing molecules. ${ }^{38}$ To assess if this was the case for present experiments, fluorescence spectra for the aged photoproducts are presented in Figure 2B. The composition of the mixture of photoproducts at the end of stage II (Scheme 1) was characterized (see Analysis of Products section to include $11.8( \pm 0.1) \mathrm{mM}$ glyoxal, $2.00( \pm 0.03) \mathrm{mM}$ formic acid, and $493( \pm 25) \mu \mathrm{M}$ oxalic acid. For comparison, the individual emission spectra of glyoxylic acid as well as the identified products at the target concentrations in a matrix with electrolytes was also registered. It was confirmed that glyoxylic, formic, and oxalic acids did not contribute to the emission spectra of the aged photolyzed sample in the interval $350 \leq \lambda_{\text {exc }}$ $\leq 400 \mathrm{~nm}$. However, Figure 2C shows similar linear correlations between the maximum wavelength of emission $\left({ }^{\mathrm{Max}} \lambda_{\mathrm{em}}\right)$ versus the excitation wavelength $\left(350 \leq \lambda_{\text {exc }} \leq 400\right.$ $\mathrm{nm}$ ) exist for the mixture of photoproducts and for aged 11.8 $\mathrm{mM}$ glyoxal (24 h in darkness) with electrolytes. We conclude the red shifting of ${ }^{\mathrm{Max}} \lambda_{\mathrm{em}}$ for longer $\lambda_{\text {exc }}$ is due to the presence of glyoxal as an individual fluorophore. Therefore, the absorption tail of aged photoproducts (Figure 1) is thought to be related to the behavior of glyoxal in the emission spectra for $\lambda_{\text {exc }} \geq 350 \mathrm{~nm}$ (Figure 2B-C). Emission measurements also confirmed no other fluorophore species (or corresponding chromophore) is present in the starting experimental mixture before photolysis, as revealed by the unchanged value of ${ }^{\mathrm{Max}} \lambda_{\mathrm{em}}$ $=441.3 \pm 2.1 \mathrm{~nm}$ for the excitation range $350 \leq \lambda_{\text {exc }} \leq 400 \mathrm{~nm}$. For the interval $280 \leq \lambda_{\text {exc }} \leq 345 \mathrm{~nm}$, the emission spectra of the aged photolyzed experiment with glyoxylic acid only displayed a practically constant value for ${ }^{\mathrm{Max}} \lambda_{\mathrm{em}}=444.1( \pm 1.8)$ $\mathrm{nm}$. The unchanged ${ }^{\mathrm{Max}} \lambda_{\mathrm{em}}$ for the wavelength interval $280-$ $345 \mathrm{~nm}$ is due to the fluorescence of unreacted glyoxylic acid.
In summary, after irradiation and initial loss of absorption, at least one new chromophore appears but the presence of $\mathrm{O}_{2}$ diminishes its production (Supporting Information). Electrolytes play a significantly different role enhancing thermochromism in stage II, implying interactions of products with electrolytes. It is important to contrast present results with previous experiments for the reaction of pyruvic acid. ${ }^{6}$ While the previous study was focused on the optical properties of complex organic matter originating from pyruvic acid in $2 \mathrm{M}$ ammonium bisulfate, this work investigates the behavior of glyoxylic acid with a mixture of electrolytes $\left(\left[\mathrm{Na}^{+}\right]=545 \mathrm{mM}\right.$, $\left[\mathrm{Cl}^{-}\right]=468 \mathrm{mM}$, and $\left.\left[\mathrm{SO}_{4}{ }^{2-}\right]=28.2 \mathrm{mM}\right)$ that does not include $\mathrm{NH}_{4}{ }^{+}$. The effect of electrolytes in present experiments agrees well with previous observations ${ }^{6}$ that electrolytes enhance thermochromism of postphotolyzed pyruvic acid solutions. Similarly, thermochromism increases with higher ionic strength (from inert electrolytes) and temperature, which may promote dehydration reactions. ${ }^{6}$

The proposed red shift in the emission spectra (Figure 2BC) resulting from the carbonyl moiety of glyoxal provides the new absorption in this kind of model system, ${ }^{6,7}$ and should contribute to the optical properties of water-extracted ambient particulate matter. ${ }^{39}$ Other atmospheric chromophoric species have been proposed to arise from the oxidation of polyhydroxylated aromatic rings into polyhydroxylated quinones absorbing in the $400-600 \mathrm{~nm}$ range. ${ }^{14}$ In addition, the direct oxidation of biomass burning and combustion emissions provided a direct link to explain the production of glyoxylic acid under humid conditions such as those found in clouds, fogs, or aqueous secondary aerosols. ${ }^{14,15}$ The rapid photobleaching of aged solutions of glyoxal by solar illumination ${ }^{40}$ was proposed to result from the loss of imines generated in reactions between carbonyls and nitrogen-containing nucleophiles. ${ }^{40}$ Our findings cannot be explained using the same concept due to the lack of imine formation, suggesting that glyoxal itself is a relevant atmospheric chromophore. Thus, photobleaching is interpreted as the disruption of chromophores' key function of interacting weakly among each other and with electrolytes. ${ }^{6,7}$

Identification of Products. Among the several methods available to study the photoreaction products of glyoxylic acid, useful information is provided by analyzing IC-ESI-MS chromatograms of photolysis products. The information from IC-ESI-MS reveals the mass-to-charge ratio $(\mathrm{m} / z)$ for anionic products present in the sample after chromatographic separation. Figure 3 shows IC chromatograms with conductivity and ESI-MS detection in the negative ion mode for the same experiment in Figure 1 before (A) and after (B) $8 \mathrm{~h}$ photolysis. Before irradiation (Figure $3 \mathrm{~A}$ ), a shoulder and two peaks elute at $11.86,12.79$, and $19.55 \mathrm{~min}$ in the conductivity detector, which are assigned with matching standards and by their $m / z$ values to (1) glyoxylate $\left(\mathrm{C}_{2} \mathrm{H}_{1} \mathrm{O}_{3}{ }^{-}, \mathrm{m} / z\right.$ 72.99), (2) chloride $\left(\mathrm{Cl}^{-}\right)$, and (3) bisulfate $\left(\mathrm{HSO}_{4}^{-}, \mathrm{m} / z\right.$ 96.99), respectively. Although $\mathrm{Cl}^{-}$could not be detected by MS, its conductivity peak was shown to grow after spike addition with a standard. Clearly, some conductivity peaks correspond to overlapping species based on the distinctive $\mathrm{m} / z$ values extracted with the help of the MS detector. Upon $8 \mathrm{~h}$ of photolysis (Figure 3B), new peaks elute at 18.60 and $20.33 \mathrm{~min}$, corresponding to two products from the photoreaction of glyoxylic acid, (4) tartrate $\left(\mathrm{C}_{4} \mathrm{H}_{5} \mathrm{O}_{6}^{-}, \mathrm{m} / z\right.$ 149.01), and (5) oxalate $\left(\mathrm{C}_{2} \mathrm{HO}_{4}^{-}, m / z 88.99\right)$, respectively.

The similar product composition found in the experiment and control $\mathrm{C}$ indicates that the presence of inorganic 


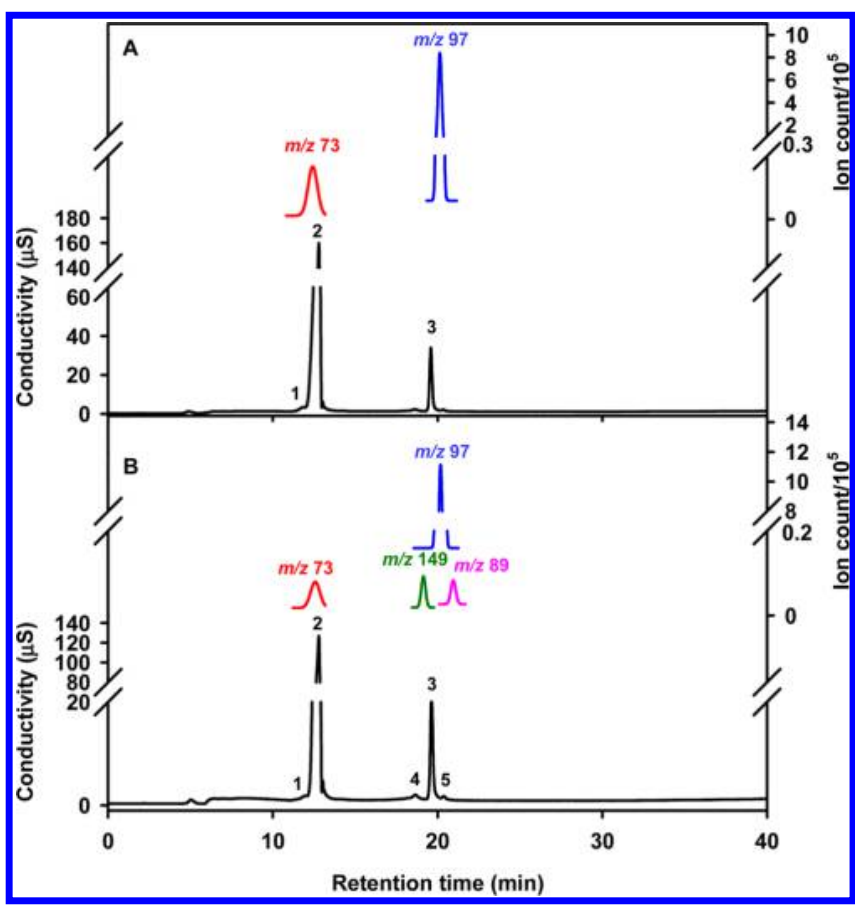

Figure 3. Ion chromatogram with conductivity and ESI-MS(-) detection for the experiment in Figure 1 (A) before and (B) after $8 \mathrm{~h}$ of irradiation. Key for peaks: (1) glyoxylic acid $(\mathrm{m} / z$ 72.99), (2) chloride, (3) sulfate $(\mathrm{m} / z$ 96.99), (4) tartaric acid $(\mathrm{m} / z$ 149.01), and (5) oxalic acid $(m / z 88.99)$.

electrolytes does not determine the formation of the low molecular weight products. Therefore, the major new photoproducts identified by IC-MS are oxalic $\left(\mathrm{C}_{2} \mathrm{H}_{2} \mathrm{O}_{4}\right)$ and tartaric $\left(\mathrm{C}_{4} \mathrm{H}_{6} \mathrm{O}_{6}\right)$ acids with molecular weights of 90.03 and 150.09 $\mathrm{amu}$, respectively. The formation of these two species requires the presence of glyoxylic acid to form the $\mathrm{C}_{2}$ - and $\mathrm{C}_{4}$-carboxylic acids. Although formic acid $(\mathrm{HCOOH})$ escaped MS detection at $m / z 45$, its presence was confirmed by IC separation with a $1.0 \mathrm{mM} \mathrm{KOH}$ isocratic gradient and conductivity detection. Instead, the production of formic acid was quantified by ${ }^{1} \mathrm{H}$ NMR.

Figure 4 shows the production of glyoxal during irradiation, as registered in the extracted ion chromatogram at $\mathrm{m} / \mathrm{z} 417.05$ for its $(\mathrm{E})$ and $(\mathrm{Z})$ hydrazones, corresponding to the reaction 2 $\mathrm{DNPH}+1$ glyoxal. While the hydrazone with $\mathrm{m} / z 417.05$ is absent before irradiation (blue trace in Figure 4), its presence is confirmed for the experiment and matched to a standard (red trace) at 7.02 and $7.65 \mathrm{~min}$. After irradiation starts, from $30 \mathrm{~min}$ to $8 \mathrm{~h}$, the concentration of glyoxal remains relatively stable [glyoxal $=2.02( \pm 0.10) \mathrm{mM}$. Therefore, during the experiment glyoxal is an intermediate that remains in steady state. The origin of glyoxal is discussed below, where its presence is also confirmed by ${ }^{13} \mathrm{C}$ NMR spectroscopy. The formation of formaldehyde $\left(\mathrm{H}_{2} \mathrm{C}=\mathrm{O}\right)$ as a primary photoproduct was discarded after performing UHPLC-MS analysis of derivatized samples. ${ }^{30}$ The hydrazone from derivatized formaldehyde would have eluted at $2.39 \mathrm{~min}$ in the extracted ion chromatogram at $m / z 209.03$, as confirmed after spike addition of the samples with a $5 \mu \mathrm{M}$ standard.

The experimental results point to the different photolytic behavior of glyoxylic acid in water and the gas-phase, where $\mathrm{CO}_{2}$ was accompanied by formaldehyde generation. ${ }^{41}$ Figure 5 shows the major products in the infrared spectrum of the gas

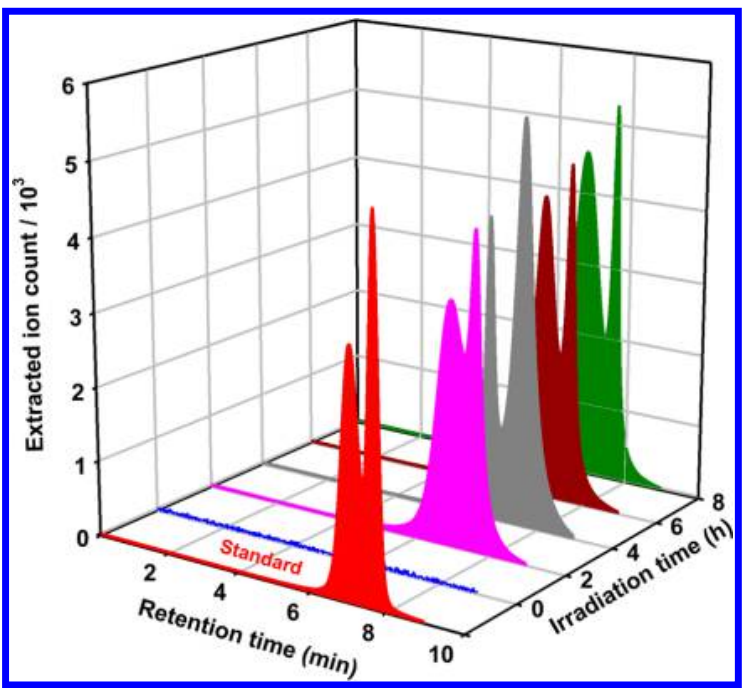

Figure 4. UHPLC-MS for the extracted ion at $m / z 417.05$ for (E) and (Z) DNPH-glyoxal hydrazones in the experiment of Figure 1. The red trace corresponds to a standard.

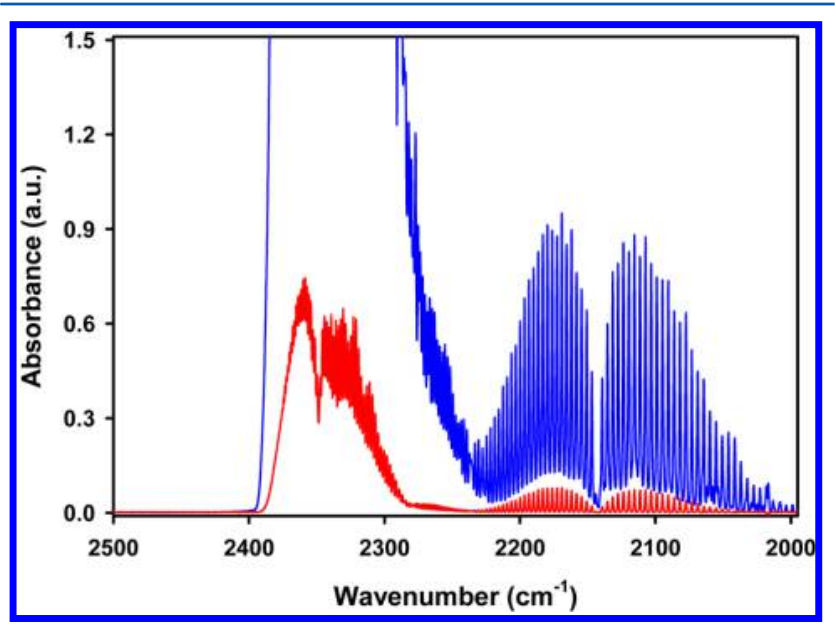

Figure 5. (Blue) Infrared spectrum of gas-phase products after photolysis $(\lambda>305 \mathrm{~nm})$ of glyoxylic acid for $8 \mathrm{~h}$. All other experimental conditions are indicated in Figure 1. The red trace shows a 1:18 dilution of the spectrum.

collected over the headspace of the reactor containing carbon dioxide $\left(\mathrm{CO}_{2}\right)$ and a lower level of carbon monoxide ( $\left.\mathrm{CO}\right)$. The spectrum shows the asymmetric stretching vibration of $\mathrm{CO}_{2}$ at $2349 \mathrm{~cm}^{-1}$, and the well-resolved $\mathrm{CO}$ bands centered at $2143 \mathrm{~cm}^{-1}$. The presence of formaldehyde was also discarded in the gaseous products because its very strong absorption at 1771 $\mathrm{cm}^{-1}$ was missing from the spectrum.

The use of ${ }^{13} \mathrm{C}$ NMR spectroscopy provides additional information from the chemical shifts $(\delta)$ of reactants and products in the photolysis mixture. 3-(Trimethylsilyl)-1propanesulfonic acid sodium salt (DSS) was added to the NMR tube as a reference $(\delta=0.00 \mathrm{ppm})$ in the aqueous solutions for all samples. Figure 6 presents the ${ }^{13} \mathrm{C}$ NMR spectrum for an experiment after $8 \mathrm{~h}$ of irradiation. In addition to the reference peak at $\delta=0.00 \mathrm{ppm}$, DSS signals also appear at $17.60,21.71$, and $56.97 \mathrm{ppm}$ in the ${ }^{13} \mathrm{C}$ NMR spectrum. The abundant gem-diol $\left(-\mathrm{C}(\mathrm{OH})_{2}\right)$ group of glyoxylic acid, with $\mathrm{sp}^{3}$ carbon, is observed at $\delta 88.89 \mathrm{ppm}$, while its carboxylic acid group $(-\mathrm{COOH})$ is at $\delta 175.90$. The $-\mathrm{COOH}$ of formic acid product is observed $\delta 179.41 \mathrm{ppm}$ in Figure 6, while oxalic acid 


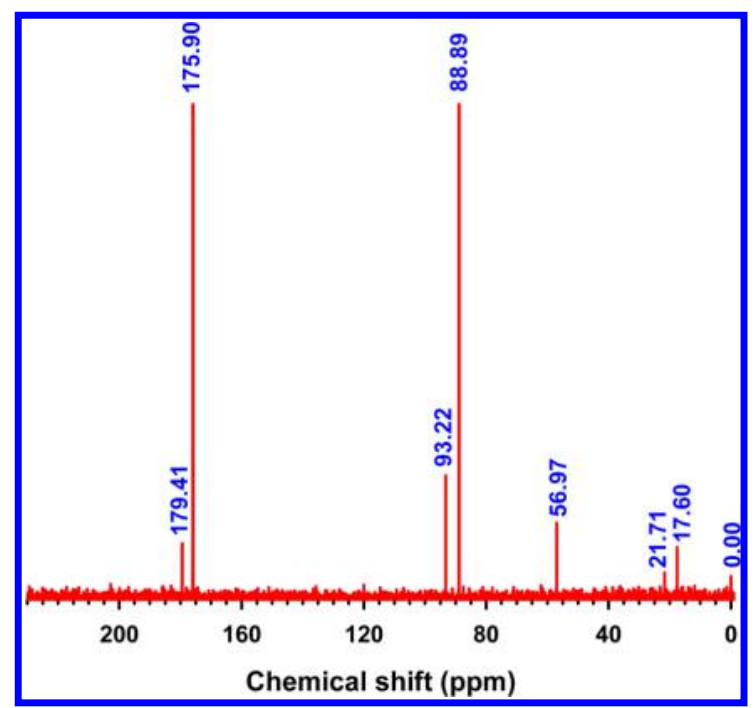

Figure 6. ${ }^{13} \mathrm{C}$ NMR spectrum after $8 \mathrm{~h}$ photolysis of glyoxylic acid under the experimental conditions given in Figure 1.

$(\delta=168.51 \mathrm{ppm})$ was only detectable after spike addition of a standard (Sigma-Aldrich, 99.7\%) to the sample. The origin of formic acid can be ascribed to the formyloxyl radical ${ }^{\bullet} \mathrm{COOH}$ created during the homolytic cleavage of excited state glyoxylic acid. This ${ }^{\bullet} \mathrm{COOH}$ radical is converted to formic acid after abstracting a hydrogen atom, for example, from dihydroxyacetic acid. However, a comparison of product yields suggests that the pathway including $\mathrm{H}$-abstraction may be as favorable as the channel resulting in $\mathrm{CO}_{2}$ evolution.

Because tartaric acid is about 10-times less abundant than oxalic acid, as quantified by IC-MS, indeed this species remains below the limit of detection in Figure 6. Spike addition of L(+)-tartaric acid (Sigma-Aldrich, 99.8\%) standard to the product mixture indicates its peaks for $-\mathrm{COOH}$ and $-\mathrm{CH}(\mathrm{OH})-$ should be observed at $\delta 177.41$ and $\delta 74.72$ ppm, respectively. Remarkably, the new peak appearing for glyoxal at $\delta 93.22 \mathrm{ppm}$ matches that of a spiked standard (Sigma-Aldrich, $38.5 \%$ ) in the products' spectrum, indicating the homolytic reaction $\mathrm{HOOC}-\mathrm{O}(\mathrm{H}) \mathrm{C}+h \nu \rightarrow \mathrm{HOOC}^{\bullet}+$ ${ }^{\circ} \mathrm{C}(\mathrm{H})=\mathrm{O}$ proceeds upon $\lambda \geq 305 \mathrm{~nm}$ irradiation.

The source of glyoxal could be linked to formyl radical recombination through the reaction: $\mathrm{O}=(\mathrm{H}) \mathrm{C}^{\bullet}+{ }^{\bullet} \mathrm{C}(\mathrm{H})=\mathrm{O}$ $\rightarrow \mathrm{O}=(\mathrm{H}) \mathrm{C}-\mathrm{C}(\mathrm{H})=\mathrm{O}$. However, more likely the addition of $\mathrm{O}=(\mathrm{H}) \mathrm{C}^{\bullet}$ to the carbonyl group of glyoxylic acid generates an alkoxy radical that, after homolysis, produces a molecule of glyoxal and a second $\mathrm{HOOC}^{\bullet}$. More details of these reactions are provided in the mechanism below.

Figure 7 shows the first-order decay of [glyoxylic acid $]_{t}$ at each time $(t)$ point relative to its initial value [glyoxylic acid $]_{0}$ during $8 \mathrm{~h}$ irradiation of stage $\mathrm{I}$, which is described by the equation [glyoxylic acid $]_{t} /[\text { glyoxylic acid }]_{0}=0.998 \times$ exp$\left(-8.85 \times 10^{-3} \mathrm{~h}^{-1} \times t\right)$ with $R^{2}=0.980$. The right-hand side vertical axis within Figure 7 displays the scale for the production of glyoxal, $\mathrm{CO}_{2}, \mathrm{CO}$, formic acid, oxalic acid, and tartaric acid for the same time series. Photoproducts can be consumed during reactions, e.g. with carbonyls or reactive radical species generated during photolysis. For example, glyoxal quickly reaches a quasi-steady state in Figure 7 with a characteristic time $\tau=7.5 \mathrm{~min}$ as described by the exponential rise to maximum fitting [glyoxal] $(\mathrm{mM})=2.04 \times(1-$ $\left.\exp \left(-5.31 \mathrm{~h}^{-1} \times t\right)\right)$ with $R^{2}=0.981$. The production of formic

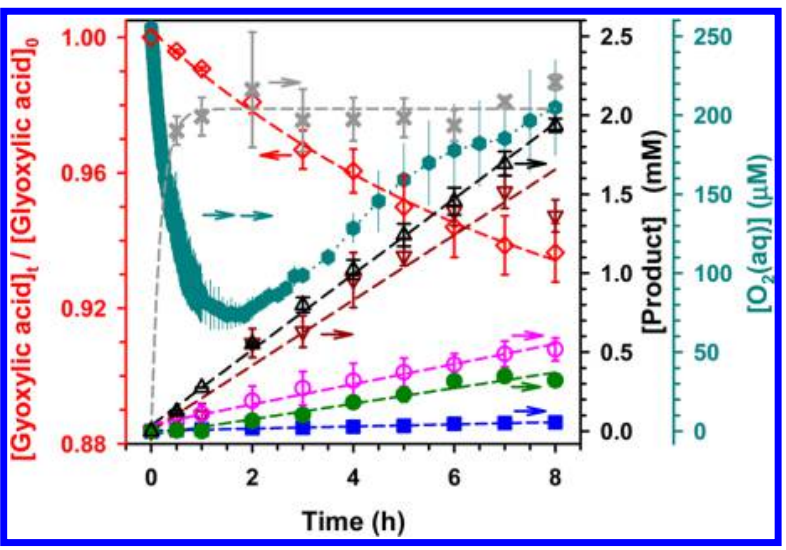

Figure 7. $($ Red $\diamond)$ Normalized loss of glyoxylic acid and production of (brown $\nabla$ ) $\mathrm{CO}_{2}$, (green $-\mathrm{CO}$, (gray $\times$ ) glyoxal, (black $\Delta$ ) formic acid, (pink $O$ ) oxalic acid, (blue $\mathbf{0}$ ) tartaric acid, and (teal hexagon) dissolved $\mathrm{O}_{2}$ during $8 \mathrm{~h}$ photolysis under the conditions given in Figure 1.

acid, $\mathrm{CO}_{2}(\mathrm{~g})$, oxalic acid, $\mathrm{CO}(\mathrm{g})$, and tartaric acid follows zeroorder kinetics with rate constants $k\left(\mathrm{mM} \mathrm{h}^{-1}\right): 2.39 \times 10^{-1}\left(R^{2}\right.$ $=0.998), 2.28 \times 10^{-1}\left(R^{2}=0.985\right.$, excluding the outlier at the $95 \%$ confidence level for $t=8 \mathrm{~h}), 6.34 \times 10^{-2}\left(R^{2}=0.980\right)$, $4.92 \times 10^{-2}\left(R^{2}=0.961\right)$, and $6.77 \times 10^{-3}\left(R^{2}=0.984\right)$, respectively. Therefore, the uniform changes observed in Figure 7 indicate the persistent photoproducts formed undergo reversible thermochromism and photobleaching in water. This versatile behavior is mainly provided by the aldehyde functional group of glyoxal and/or its derived material in the mixture. Finally, it is important to indicate that the behavior of dissolved oxygen in this experimental system is quite different to that reported in studies with methyl vinyl ketone. ${ }^{42,43}$ Under irradiation, $\left[\mathrm{O}_{2}(\mathrm{aq})\right]$ in Figure 7 (external right-hand side vertical axis) only decreases $70 \%$ (from $0.26 \mathrm{mM}$ to $0.08 \mathrm{mM}$ ) within the first $2 \mathrm{~h}$, and then recovers close to $80 \%$ of the expected equilibrium concentration. In other words, the production of species that consume $\mathrm{O}_{2}(\mathrm{aq})$ is never large enough to completely deplete this important gas in solution during the whole experiment.

Proposed Reaction Mechanism. From the experiments described in the discussion above, a mechanism for the photoreaction of glyoxylic acid via radical chemistry is proposed in Scheme 2. The proposed mechanism, which advances previous knowledge in this field, serves as a first representation that could be further improved in the future. Dissolved organic matter, including triplet-state carbonyls, can play a significant role as a photosensitizer in the environment. ${ }^{44,45}$ For example, the oligomerization of methyl vinyl ketone proceeds after reaction with $\mathrm{OH}$ or excited state pyruvic acid in water. ${ }^{42,43}$ In present experiments, as for other carbonyls and due to its absorbing tail for $\lambda \geq 300 \mathrm{~nm}$, the lowest energy $n \rightarrow \pi^{*}$ transition is activated by solar light to produce a very reactive singlet excited state of glyoxylic acid. The singlet excited state can be considered to react directly, or undergo intersystem crossing producing a triplet, which can then react, as it has been suggested for the gas-phase photolysis of glyoxylic acid. ${ }^{41}$ Therefore, Scheme 2 depicts a generic excited state glyoxylic acid GA* to be produced upon photon absorption by reaction R1.

The excited state $\mathrm{GA}^{*}$ can react directly undergoing homolytic cleavage by reaction $\mathrm{R} 2$ into formyl-oxyl radical HOOC $^{\bullet}$ and formyl radical ${ }^{\bullet} \mathrm{C}(\mathrm{H})=\mathrm{O}$, the simplest existing 
Scheme 2. Proposed Mechanism for the Photooxidation of Glyoxylic Acid (GA) in Water

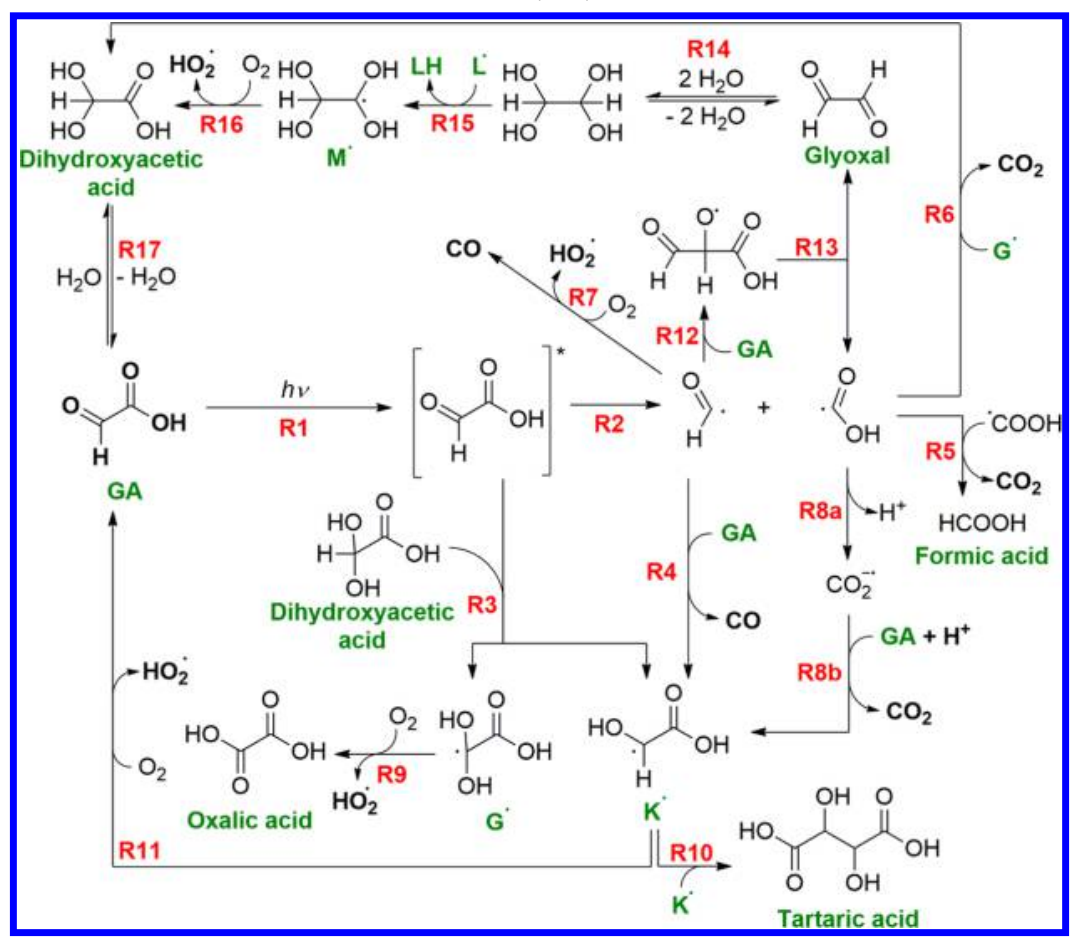

acyl radical. The alternative fate of $\mathrm{GA}^{*}$, as a triplet, is to abstract a hydrogen atom from the very abundant hydrate of glyoxylic acid via reaction $\mathrm{R} 3$ to generate the radicals of glycolic acid $\left(\mathrm{K}^{\bullet}\right)$ and dihydroxyacetic acid $\left(\mathrm{G}^{\bullet}\right)$. Hydrated glyoxylic acid cannot accept energy from $\mathrm{GA}^{*}$ but hydrogen abstraction is a characteristic reaction of triplet 2-oxocarboxylic acids. ${ }^{46}$ The doublet displayed in electron paramagnetic resonance measurements in the liquid phase ${ }^{47}$ shows that $\mathrm{K}^{\bullet}$ can also be generated when $\mathrm{H}$-abstraction from glycolic acid occurs. Similarly, $\mathrm{G}^{\bullet}$ corresponds to a triplet previously registered during the reduction of oxalic acid at low $\mathrm{pH}^{48}$

Reaction R4 (Scheme 2) generates carbon monoxide from ${ }^{\circ} \mathrm{C}(\mathrm{H})=\mathrm{O}$ and also provides a pathway to form $\mathrm{K}^{\bullet}$ from $\mathrm{GA}^{49}$ The acid dissociation constant of $\mathrm{HOOC}^{\bullet}\left(\mathrm{p} K_{\mathrm{a}}=2.3\right)^{50}$ indicates that $95 \%$ of the speciation of this radical at the experimental condition of $\mathrm{pH} 1.0$ is in the undissociated form. Interestingly, the fate of the conjugated base $\mathrm{CO}_{2}^{\circ-}$ for the $\mathrm{pH}$ range 3-9, is to form oxalate through bimolecular recombina-

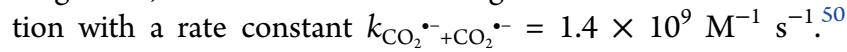
However, at lower $\mathrm{pH}$ (e.g., $\mathrm{pH}$ 1.0) the yield of oxalate from the previous reaction becomes negligible while the yield of $\mathrm{CO}_{2}$ increases. ${ }^{50}$ Therefore, discarding the recombination reaction $\mathrm{HOOC}^{\bullet}+{ }^{\bullet} \mathrm{C}(\mathrm{H})=\mathrm{O} \rightarrow \mathrm{HOOC}-\mathrm{C}(\mathrm{H})=\mathrm{O}$ as viable under continuous irradiation, the fate of $\mathrm{HOOC}^{\bullet}$ at low $\mathrm{pH}$ is (1) to self-disproportionate with rate constant $k_{\mathrm{HOOC}}{ }^{\circ} \mathrm{HOOC}^{\circ}=1.7 \times$ $10^{9} \mathrm{M}^{-1} \mathrm{~s}^{-1}$ (reported at $\left.\mathrm{pH} 0\right)^{51}$ into $\mathrm{CO}_{2}$ and $\mathrm{HCOOH}$ by reaction $\mathrm{R} 5$ (Scheme 2); ${ }^{50}$ (2) to react with another radical, ${ }^{49}$ that is, to produce $\mathrm{CO}_{2}$ and regenerate the hydrate form of glyoxylic acid by reaction R6; or (3) to react with ${ }^{\circ} \mathrm{C}(\mathrm{H})=\mathrm{O}$ to yield formic acid and $\mathrm{CO} .{ }^{49}$ Carbon monoxide can also be generated from the formyl radical in the presence of dissolved $\mathrm{O}_{2}$ by reaction $\mathrm{R} 7$ that eliminates hydroperoxyl radical $\left(\mathrm{HO}_{2}{ }^{\circ}\right) .^{52}$ As indicated above, $\mathrm{CO}_{2}^{\bullet-}$ formed by reaction $\mathrm{R} 8 \mathrm{a}$ can undergo efficient acid catalyzed reaction with glyoxylic acid to release $\mathrm{CO}_{2}(\mathrm{~g})$ and $\mathrm{K}^{\bullet}$ by reaction $\mathrm{R} 8 \mathrm{~b}$. At very acidic $\mathrm{pH}$, the sequence $\mathrm{R} 8 \mathrm{a}+\mathrm{R} 8 \mathrm{~b}$ proceeds directly from $\mathrm{HOOC}^{\bullet}+\mathrm{GA}$.
Alternatively, HOOC ${ }^{\bullet}$ could abstract a hydrogen ${ }^{49}$ from dihydroxyacetic acid to produce formic acid and $\mathrm{G}^{\bullet}$.

The production of oxalic acid observed can be explained by the direct oxidation of $\mathrm{G}^{\bullet}$ after combining with $\mathrm{O}_{2}$ and in situ elimination of hydroperoxyl radical via reaction R9. ${ }^{53}$ Once oxalic acid is formed, it can undergo in situ reduction to form $\mathrm{G}^{\bullet}$ again by any of the $\alpha$-hydroxyalkyl radicals available in the system. ${ }^{47}$ The combination of two $\mathrm{K}^{\circ}$ radicals via reaction $\mathrm{R} 10$, with rate constant $k_{\mathrm{K}^{\bullet}+\mathrm{K}^{\bullet}}=5.5 \times 10^{8} \mathrm{M}^{-1} \mathrm{~s}^{-1},{ }^{54}$ results in the formation of tartaric acid, a less likely process for the fate of this radical, as represented by the low level of product quantified. As observed for the production of dimethyltartaric acid from the recombination of lactic acid radicals in the photolysis of pyruvic acid, ${ }^{3,4}$ the pathway for the production of tartaric acid in this work is not fully quenched in the presence of $\left[\mathrm{O}_{2}(\mathrm{aq})\right]_{1 \text { atmair }}=$ $0.26 \mathrm{mM}$. The recombination of $\alpha$-hydroxyperoxyl radicals should become more important at higher radical concentration than $5 \times 10^{-9} \mathrm{M}^{55}$ and also as proposed here for decreasing $\left[\mathrm{O}_{2}\right]$ found at higher altitudes. The reaction of $\mathrm{K}^{\bullet}$ with $\mathrm{O}_{2}$ proceeds by reaction $\mathrm{R} 11$, with a rate constant $k_{\mathrm{K}^{\circ}+\mathrm{O}_{2}}=1.76 \times$ $10^{9} \mathrm{M}^{-1} \mathrm{~s}^{-1}, 56$ to regenerate the carbonyl-form of glyoxylic acid after elimination of hydroperoxyl radical with a rate constant $k_{\mathrm{KO}_{2}}=122 \mathrm{~s}^{-1.55}$

An alkoxy radical is generated following the addition of - $\mathrm{C}(\mathrm{H})=\mathrm{O}$ to the carbonyl group of glyoxylic acid (reaction $\mathrm{R} 12$, Scheme 2). It has been previously proposed that at high $\mathrm{pH}$ the semidione radical would be an important intermediate. $^{47}$ The production of glyoxal in reaction R13 is proposed to result from the cleavage of the alkoxy radical formed in reaction R12. Reaction R13 simultaneously generates a second source of - $\mathrm{COOH}$ that contributes $\mathrm{CO}_{2}$, the major reaction product. It is important to highlight that the presence of carbonyls (e.g., glyoxylic acid or in situ produced glyoxal) acting as sensitizers can result in a positive feedback for the production of $\mathrm{CO}_{2}{ }^{47}$ Because the possible recombination of two ${ }^{\circ} \mathrm{C}(\mathrm{H})=\mathrm{O}$ radicals 
seems an unlikely process (i.e., the recombination of two - $\mathrm{COOH}$ yields little oxalic acid), a reaction such as R13 is thought to dominate the production of glyoxal. The carbonyl group of the alkoxy radical formed in reaction R12 likely undergoes fast hydration and actually generates the monohydrate of glyoxal, which incorporates a second molecule of water $\left(K_{\text {hyd }}=2.2 \times 10^{5}\right)^{57}$ to produce the unique tetrol signal observed in the ${ }^{13} \mathrm{C}$ NMR spectrum (equilibrium R14, Scheme 2). ${ }^{57}$

Reaction R15 shows that hydrogen abstraction by any of the radicals present in the system, denoted by the generic radical $\mathrm{L}^{\bullet}$, yields the hydrated glyoxal radical. In reaction $\mathrm{R} 16$, the hydrated glyoxal radical $\mathrm{M}^{\bullet}$ combines with $\mathrm{O}_{2}$ forming the glyoxyl peroxyl radical $\mathrm{MO}_{2}^{\circ}$ with a rate constant $k_{\mathrm{M}^{\circ}+\mathrm{O}_{2}}=1.1 \times$ $10^{9} \mathrm{M}^{-1} \mathrm{~s}^{-1} .55$ After elimination of $\mathrm{HO}_{2}{ }^{\bullet}$, also included in reaction $\mathrm{R} 16\left(k_{\mathrm{MO}_{2}}^{\bullet}=122 \mathrm{~s}^{-1}\right){ }^{55}$ the gem-diol form of glyoxylic acid is generated, which is in equilibrium R17 $\left(K_{\mathrm{Hyd}}=300\right)^{31}$ with the carbonyl form of glyoxylic acid. Alternatively, disproportionation during the recombination of $\mathrm{MO}_{2}^{\circ}$ radicals ${ }^{52}$ produces glyoxal and glyoxylic acid. Different carbonyls have been shown to favor both $\alpha$-cleavage and hydrogen abstraction occurring simultaneously during primary photochemical reactions $^{58}$ and glyoxylic acid is not the exception. For this mechanism, reactions $\mathrm{G}^{\bullet}+\mathrm{G}^{\bullet}, \mathrm{G}^{\bullet}+\mathrm{K}^{\bullet}, \mathrm{G}^{\bullet}+\mathrm{M}^{\bullet}$, and $\mathrm{K}^{\bullet}+\mathrm{M}^{\bullet}$ were considered and disregarded because no corresponding products with $\mathrm{m} / z 165181,183$, and 167 were found in the ICMS chromatogram. Remarkably, despite the low levels of products generated in the condensed phase, this mechanism clearly highlights the importance of understanding further mechanistic steps occurring in atmospheric waters. The mechanism provides details of several reactions (i.e., R7, R9, $\mathrm{R} 11$, and R16) capable of generating reactive oxygen species in situ from a photoinitiated process previously unknown.

It is interesting to contrast the effect of dissolved $\mathrm{O}_{2}$ in the formation of both $\mathrm{CO}_{2}(\mathrm{~g})$ and $\mathrm{CO}(\mathrm{g})$ in experiments supersaturated in $\mathrm{O}_{2}(\mathrm{~g})\left(\left[\mathrm{O}_{2}(\mathrm{aq})\right]_{0}=1.24 \mathrm{mM}\right)$ vs 1 atm $\mathrm{N}_{2}(\mathrm{~g})$. For this purpose, the evolution of $\mathrm{CO}_{2}(\mathrm{~g})$ and $\mathrm{CO}(\mathrm{g})$ during irradiation was monitored for [glyoxylic acid] $=5,25$, 100 , and $250 \mathrm{mM}$ in the electrolyte matrix during irradiation. The ratio of the initial rates of $\mathrm{CO}_{2}(\mathrm{~g})$ and $\mathrm{CO}(\mathrm{g})$ formation to $I_{0}$ were employed to calculate the corresponding apparent quantum yields $\Phi_{\mathrm{CO}_{2}}$ and $\Phi_{\mathrm{CO}}$ displayed in Figure S4. The fact that the ratio of quantum yields (Figure S4) in the presence of dissolved oxygen is always larger than the corresponding ratio under 1 atm $\mathrm{N}_{2}(\mathrm{~g}),\left(\Phi_{\mathrm{CO}_{2}} / \Phi_{\mathrm{CO}}\right)_{\mathrm{O}_{2}}>\left(\Phi_{\mathrm{CO}_{2}} / \Phi_{\mathrm{CO}}\right)_{\mathrm{N}_{2}}$, clearly indicates that $\mathrm{O}_{2}(\mathrm{aq})$ favors the formation of $\mathrm{CO}_{2}(\mathrm{~g})$, the fully oxidized product. The values of $\Phi_{\mathrm{CO}_{2}}$ are enhanced for larger [glyoxylic acid], suggesting that some bimolecular processes and/or the participation of reaction intermediates could be important to facilitate $\mathrm{CO}_{2}$ production during irradiation. In contrast, $\Phi_{\mathrm{CO}}$ appears to follow a similar growing trend for increasing [glyoxylic acid] with dissolved $\mathrm{O}_{2}(\mathrm{~g})$ or $\mathrm{N}_{2}(\mathrm{~g})$, suggesting the production of $\mathrm{CO}(\mathrm{g})$ has a much smaller dependence on $\left[\mathrm{O}_{2}(\mathrm{aq})\right]$ than $\mathrm{CO}_{2}(\mathrm{~g})$ does. For the two higher [glyoxylic acid] (Figure S4), the significant difference in $\Phi_{\mathrm{CO}}$ under supersaturated dissolved oxygen versus $\mathrm{N}_{2}(\mathrm{~g})$ might be attributed to reaction R7 (Scheme 2) with direct participation of $\mathrm{O}_{2}(\mathrm{aq})$. A related conclusion can be drawn from the larger quasi-steady state glyoxal production obtained by extrapolating the $[\text { glyoxal }]_{\text {inf }}$ as time $\rightarrow \infty$ (Figure S5) without dissolved $\mathrm{O}_{2}$. Figure $\mathrm{S} 5$ suggests that $\mathrm{O}_{2}(\mathrm{aq})$ in reaction R7 decreases the availability of ${ }^{\bullet} \mathrm{C}(\mathrm{H})=\mathrm{O}$ for the glyoxal production channel $\mathrm{R} 12+\mathrm{R} 13$. Indeed, the growing trends for $\Phi_{\mathrm{CO}_{2}}$ and $\Phi_{\mathrm{CO}}$ with increasing [glyoxylic acid] provide mechanistic support for direct reactions R4 and R8a + $\mathrm{R} 8 \mathrm{~b}$, and indirectly by enhancing the production of $\mathrm{G}^{\bullet}$ in reaction $\mathrm{R} 3$, which is available to facilitate the decarboxylation R6. A related discussion of the effect of $\left[\mathrm{O}_{2}(\mathrm{aq})\right]$ and [glyoxylic acid $]_{0}$ in the production of formic, oxalic, and tartaric acids is presented in the Supporting Information.

\section{CONCLUSIONS AND ATMOSPHERIC IMPLICATIONS}

Addressing the significance of aqueous photochemistry in the processing of atmospheric particles is an important issue. ${ }^{1,2,59}$ However, uncertainties in this field remain because photolysis quantum yields for many compounds are unknown. ${ }^{59}$ The data in this work allow us to report for the first time an overall quantum yield for the photolytic loss of aqueous glyoxylic acid $\left(\Phi_{-G A}\right)$ in air under solar irradiation. The ratio of the initial reaction rate of aqueous glyoxylic acid in the experiment of Figure $7,(-\mathrm{d}[\mathrm{GA}] / \mathrm{d} t)_{0}=6.75 \times 10^{-7} \mathrm{~mol} \mathrm{~L}^{-1} \mathrm{~s}^{-1}$, to $I_{0}$ provides $\Phi_{-\mathrm{GA}}=0.017$ for $\lambda=325( \pm 20) \mathrm{nm}$. This value can be used to estimate the photolysis rate in the aqueous phase $\left(j_{a q}\right)$ from the integral of the variable actinic flux $F_{\mathrm{A}}$ and the cross section of glyoxylic acid $\sigma_{\lambda}: j_{\text {aq }}=\int F_{\mathrm{A}}(\lambda) \Phi(\lambda) \sigma(\lambda) \mathrm{d} \lambda$. Available data for surface altitude, a solar zenith angle of $40^{\circ}$, and a surface albedo of $80 \%$ is chosen to represent $F_{\mathrm{A}},{ }^{60}$ while $\sigma_{\lambda}$ is estimated from the known concentration that simulates atmospheric conditions (Supporting Information) and the corresponding absorbance values in Figure 1. Thus, under atmospheric conditions a value of $j_{\mathrm{aq}}=9.9 \times 10^{-7} \mathrm{~s}^{-1}$ is obtained, the reciprocal of which can be used to estimate a rough photolysis lifetime in the aqueous phase of $\tau \approx 11 \mathrm{~d}$. For comparison, the loss of glyoxylic acids by indirect photolysis in the aqueous phase proceeds only two times faster (e.g, $\left.\tau_{\mathrm{aq}, \mathrm{GA}+\mathrm{OH}} \approx 5 \mathrm{~d}\right) .{ }^{61}$ While the rate constant for the gas phase reaction glyoxylic acid $+{ }^{\bullet} \mathrm{OH}$ is unknown, structure activity relationships give an estimated $k_{\mathrm{GA}+\mathrm{OH}}=1.28 \times 10^{-11} \mathrm{~cm}^{3}$ molecule $\mathrm{e}^{-1} \mathrm{~s}^{-159}$ Using an average daytime $[\mathrm{OH}(\mathrm{g})] 1.6 \times 10^{6}$ molecules $\mathrm{cm}^{-3}$ leads to a lifetime $\tau_{\mathrm{gas}, \mathrm{GA}+\mathrm{OH}} \approx 0.56$ day. The large gas phase photolysis rate of glyoxylic acid $j_{\text {gas }}=8.7 \times 10^{-5}$ $\mathrm{s}^{-1}$ provides a shorter lifetime $\tau_{\mathrm{gas}, \mathrm{h} \nu}=3.2 \mathrm{~h} .{ }^{17}$ However, as the hydration equilibrium of glyoxylic acid is shifted toward 2,2dihydroxyacetic acid, this species preferentially and quickly partitions to the particle phase. ${ }^{32}$ Because of the improbable presence of glyoxylic acid in the gas-phase, its fate should not be dominated by reactivity with ${ }^{\circ} \mathrm{OH}(\mathrm{g})$ radical.

This work studies for the first time the photoreaction of aqueous glyoxylic acid under simulated solar irradiation and thermal processing of the photolyzed in the dark. The mechanism proposed via radicals is initiated by a photoexcited $\alpha$-dicarbonyl species in water and results in the production of species with large $\mathrm{O}: \mathrm{C}$ ratio. The results provide an explanation to the possible role of glyoxylic acid in the generation of complex organic matter in aqueous aerosols. Although glyoxylic acid is not a major absorber of solar radiation, the tail of its electronic spectrum is extended well into the region of solar actinic radiation available in the troposphere. After light absorption, glyoxylic acid can induce secondary reactivity of other molecules as demonstrated here. This information contributes new experimental evidence to explain the mechanisms of aqSOA production of oxalic acid and establishes 
a link to glyoxal chemistry. The low production of tartaric acid, a dimer of a primary radical, is also detected. However, it is clear that glyoxylic acid is also converted to carbon oxides.

Experiments and controls have also explored the effects caused by inorganic electrolytes and $\left[\mathrm{O}_{2}(\mathrm{aq})\right]$. Chemical identification is obtained from a combination of spectroscopies that supports the direct participation of radicals in the mechanism. In addition, this work has contrasted the optical properties showing the periodic behavior of samples during daytime and nighttime cycles of photobleaching and thermochromism, respectively. Overall, the optical properties of atmospheric brown carbon species change periodically in the aqueous-phase. $\mathrm{O}_{2}(\mathrm{~g})$ in air cannot stop the development of thermochromism, affecting minimally the optical properties of the model organic material produced, which in the atmosphere is influenced by aerosols' variable and complex size, structure, and composition. These results are directly related to the ulterior oxidative fate of polyphenols emitted during biomass burning and combustion processes, which have been proposed to contribute chromophores and reactive intermediates in route to the formation of the dicarbonyl, oxo-carboxylic acid, and dicarboxylic acid components of brown carbon. ${ }^{14,15}$ In particular, oxocarboxylic acids are important species in the atmosphere because they participate in aqueous-phase reactions in the presence of electrolytes. The observed behavior of model organic species should be treated in future climate change models taking into account thermochromism and photobleaching parametrization factors.

\section{ASSOCIATED CONTENT}

\section{S Supporting Information}

The Supporting Information is available free of charge on the ACS Publications website at DOI: 10.1021/acs.jpca.6b00225.

Detailed experimental section, additional characterization of starting material and effects of dissolved oxygen on products formation, Figures S1-S6, and Table S1 (PDF)

\section{AUTHOR INFORMATION}

\section{Corresponding Author}

*E-mail: marcelo.guzman@uky.edu. Tel: 859-323-2892.

\section{Notes}

The authors declare no competing financial interest.

\section{ACKNOWLEDGMENTS}

We thank research funding from the National Science foundation under NSF CAREER award CHE-1255290.

\section{ABBREVIATIONS}

aqSOA, aqueous secondary organic aerosol; DNPH, 2,4dinitrophenylhydrazine; DSS, 3-(trimethylsilyl)-1-propanesulfonic acid sodium salt; GA, glyoxylic acid; $\mathrm{G}^{\bullet}$, dihydroxyacetic acid radical; int, integral; $\mathrm{K}^{\bullet}$, glycolic acid radical; $K_{\text {hyd }}$ carbonyl hydration equilibrium constant; $K_{\mathrm{H}}$, Henry's law constant; $\mathrm{L}^{\bullet}$, a generic radical; $\mathrm{M}^{\bullet}$, hydrated glyoxal radical; $\mathrm{MO}_{2}^{\bullet}$, glyoxyl peroxyl radical; $\delta$, chemical shift

\section{REFERENCES}

(1) Ervens, B. Modeling the processing of aerosol and trace gases in clouds and fogs. Chem. Rev. 2015, 115, 4157-4198.

(2) McNeill, V. F. Aqueous organic chemistry in the atmosphere: Sources and chemical processing of organic aerosols. Environ. Sci. Technol. 2015, 49, 1237-1244.
(3) Guzman, M. I.; Colussi, A. J.; Hoffmann, M. R. Photoinduced oligomerization of aqueous pyruvic acid. I. Phys. Chem. A 2006, 110, 3619-3626.

(4) Guzmán, M.; Hoffmann, M.; Colussi, A. Photolysis of pyruvic acid in ice: Possible relevance to $\mathrm{CO}$ and $\mathrm{CO}_{2}$ ice core record anomalies. I. Geophys. Res. 2007, 112, D10123.

(5) Guzman, M. I.; Colussi, A. J.; Hoffmann, M. R. Photogeneration of distant radical pairs in aqueous pyruvic acid glasses. $I$.Ph $\psi$ s. Chem.A 2006, 110, 931-935.

(6) Rincon, A. G.; Guzman, M. I.; Hoffmann, M. R.; Colussi, A. J. Thermochromism of model organic aerosol matter. I. Phvs. Chem. Lett. 2010, 1, 368-373.

(7) Rincon, A. G.; Guzman, M. I.; Hoffmann, M. R.; Colussi, A. J. Optical absorptivity versus molecular composition of model organic aerosol matter. I. Phys. Chem. A 2009, 113, 10512-10520.

(8) Das, S.; Bhattacharyya, J.; Mukhopadhyay, S. Mechanistic studies on the oxidation of glyoxylic and pyruvic acid by a $\left[\mathrm{Mn}_{4} \mathrm{O}_{6}\right]^{4+}$ core in aqueous media: Kinetics of oxo-bridge protonation. Helv. Chim. Acta 2006, 89, 1947-1958.

(9) Carlton, A. G.; Turpin, B. J.; Lim, H. J.; Altieri, K. E.; Seitzinger, S. Link between isoprene and secondary organic aerosol (SOA): Pyruvic acid oxidation yields low volatility organic acids in clouds. Geophvs. Res. Lett. 2006, 33, L06822.

(10) Ervens, B.; Carlton, A. G.; Turpin, B. J.; Altieri, K. E.; Kreidenweis, S. M.; Feingold, G. Secondary organic aerosol yields from cloud-processing of isoprene oxidation products. Geophvs. Res. Lett. 2008, 35, L02816.

(11) Nguyen, T. B.; Bateman, A. P.; Bones, D. L.; Nizkorodov, S. A.; Laskin, J.; Laskin, A. High-resolution mass spectrometry analysis of secondary organic aerosol generated by ozonolysis of isoprene. Atmos. Environ. 2010, 44, 1032-1042.

(12) Martín-Reviejo, M.; Wirtz, K. Is benzene a precursor for secondary organic aerosol? Environ. Sci. Technol. 2005, 39, 1045-1054.

(13) Bloss, C.; Wagner, V.; Jenkin, M.; Volkamer, R.; Bloss, W.; Lee, J.; Heard, D.; Wirtz, K.; Martin-Reviejo, M.; Rea, G.; et al. Development of a detailed chemical mechanism (MCMv3. 1) for the atmospheric oxidation of aromatic hydrocarbons. Atmos. Chem. Phvs. 2005, 5, 641-664.

(14) Pillar, E. A.; Camm, R. C.; Guzman, M. I. Catechol oxidation by ozone and hydroxyl radicals at the air-water interface. Environ. Sci. Technol. 2014, 48, 14352-14360.

(15) Pillar, E. A.; Zhou, R.; Guzman, M. I. Heterogeneous oxidation of catechol. I. Phys. Chem. A 2015, 119, 10349-10359.

(16) Chang, J. L.; Thompson, J. E. Characterization of colored products formed during irradiation of aqueous solutions containing $\mathrm{H}_{2} \mathrm{O}_{2}$ and phenolic compounds. Atmos. Environ. 2010, 44, 541-551.

(17) Warneck, P. Multi-phase chemistry of $\mathrm{C}_{2}$ and $\mathrm{C}_{3}$ organic compounds in the marine atmosphere. I. Atmos. Chem. 2005, 51, 119159.

(18) Kawamura, K.; Tachibana, E.; Okuzawa, K.; Aggarwal, S.; Kanaya, Y.; Wang, Z. High abundances of water-soluble dicarboxylic acids, ketocarboxylic acids and $\alpha$-dicarbonyls in the mountaintop aerosols over the North China Plain during wheat burning season. Atmos. Chem. Phys. 2013, 13, 8285-8302.

(19) Fu, P.; Kawamura, K.; Usukura, K.; Miura, K. Dicarboxylic acids, ketocarboxylic acids and glyoxal in the marine aerosols collected during a round-the-world cruise. Mar. Chem. 2013, 148, 22-32.

(20) Mkoma, S.; Kawamura, K. Molecular composition of dicarboxylic acids, ketocarboxylic acids, $\alpha$-dicarbonyls and fatty acids in atmospheric aerosols from Tanzania, East Africa during wet and dry seasons. Atmos. Chem. Phvs. 2013, 13, 2235-2251.

(21) Lin, G.; Sillman, S.; Penner, J. E.; Ito, A. Global modeling of SOA: the use of different mechanisms for aqueous-phase formation. Atmos. Chem. Phys. 2014, 14, 5451-5475.

(22) Bao, L.; Matsumoto, M.; Kubota, T.; Sekiguchi, K.; Wang, Q.; Sakamoto, K. Gas/particle partitioning of low-molecular-weight dicarboxylic acids at a suburban site in Saitama, Japan. Atmos. Environ. 2012, 47, 546-553. 
(23) Harvey, H. W. The Chemistry and Fertility of Sea Waters, 2nd ed.; Cambridge University Press: New York, 1957.

(24) Guzman, M. I.; Athalye, R. R.; Rodriguez, J. M. Concentration effects and ion properties controlling the fractionation of halides during aerosol formation. I. Phys. Chem. A 2012, 116, 5428-5435.

(25) Noziere, B.; Dziedzic, P.; Córdova, A. Products and kinetics of the liquid-phase reaction of glyoxal catalyzed by ammonium ions $\left(\mathrm{NH}_{4}^{+}\right)$. I. Phvs. Chem. A 2009, 113, 231-237.

(26) Manahan, S. E. Environmental Chemistry, 9th ed.; CRC Press: Boca Raton, FL, 2010.

(27) Zhou, R; Guzman, M. I. $\mathrm{CO}_{2}$ reduction under periodic illumination of $\mathrm{ZnS}$. I. Phys. Chem. C 2014, 118, 11649-11656.

(28) Zhou, R.; Guzman, M. I. Photocatalytic reduction of fumarate to succinate on $\mathrm{ZnS}$ mineral surfaces. I. Phys. Chem. C 2016, 120, 73497357.

(29) Görner, H.; Kuhn, H. J. Photodecarboxylation of phenylglyoxylic acid: Influence of para-substituents on the triplet state properties. J. Chem. Soc., Perkin Trans. 2 1999, 2671-2680.

(30) Eugene, A. J.; Xia, S.-S.; Guzman, M. I. Negative production of acetoin in the photochemistry of aqueous pyruvic acid. Proc. Natl. Acad. Sci. U. S. A. 2013, 110, E4274-E4275.

(31) Sorensen, P. E.; Bruhn, K.; Lindelov, F.; et al. Kinetics and equilibria for the reversible hydration of the aldehyde group in glyoxylic acid. Acta Chem. Scand. 1974, 28, 162-168.

(32) Plath, K. L.; Axson, J. L.; Nelson, G. C.; Takahashi, K.; Skodje, R. T.; Vaidaa, V. Gas-phase vibrational spectra of glyoxylic acid and its gem diol monohydrate. Implications for atmospheric chemistry. React. Kinet. Catal. Lett. 2009, 96, 209-224.

(33) Guzman, M. I.; Hildebrandt, L.; Colussi, A. J.; Hoffmann, M. R. Cooperative hydration of pyruvic acid in ice. I. Am. Chem. Soc. 2006, 128, 10621-10624.

(34) Shapiro, E. L.; Szprengiel, J.; Sareen, N.; Jen, C. N.; Giordano, M. R.; McNeill, V. F. Light-absorbing secondary organic material formed by glyoxal in aqueous aerosol mimics. Atmos. Chem. Phys. 2009, 9, 2289-2300.

(35) Updyke, K. M.; Nguyen, T. B.; Nizkorodov, S. A. Formation of brown carbon via reactions of ammonia with secondary organic aerosols from biogenic and anthropogenic precursors. Atmos. Environ. 2012, 63, 22-31.

(36) Jones, M.; Fleming, S. A. Organic Chemistry, 4th ed.; W. W. Norton \& Company Inc.: New York, 2010.

(37) Laskin, A.; Laskin, J.; Nizkorodov, S. A. Chemistry of Atmospheric Brown Carbon. Chem. Rev. 2015, 115, 4335-4382.

(38) Lin, P.; Laskin, J.; Nizkorodov, S. A.; Laskin, A. Revealing brown carbon chromophores produced in reactions of methylglyoxal with ammonium sulfate. Environ. Sci. Technol. 2015, 49, 14257-14266.

(39) Phillips, S. M.; Smith, G. D. Light absorption by charge transfer complexes in brown carbon aerosols. Environ. Sci. Technol. Lett. 2014, $1,382-386$.

(40) Zhao, R.; Lee, A. K. Y.; Huang, L.; Li, X.; Yang, F.; Abbatt, J. P. D. Photochemical processing of aqueous atmospheric brown carbon. Atmos. Chem. Phys. 2015, 15, 6087-6100.

(41) Back, R. A.; Yamamoto, S. The gas-phase photochemistry and thermal decomposition of glyoxylic acid. Can. J. Chem. 1985, 63, 542548.

(42) Renard, P.; Reed Harris, A. E.; Rapf, R. J.; Ravier, S.; Demelas, C.; Coulomb, B.; Quivet, E.; Vaida, V.; Monod, A. Aqueous phase oligomerization of methyl vinyl ketone by atmospheric radical reactions. I. Phys. Chem. C 2014, 118, 29421-29430.

(43) Renard, P.; Siekmann, F.; Gandolfo, A.; Socorro, P.; Salque, G.; Ravier, S.; Quivet, E; Clément, J. L.; Traikia, M.; Delort, A. M.; et al. Radical mechanisms of methyl vinyl ketone oligomerization through aqueous phase $\mathrm{OH}$-oxidation: on the paradoxical role of dissolved molecular oxygen. Atmos. Chem. Phvs. 2013, 13, 6473-6491.

(44) Ciuraru, R.; Fine, L.; van Pinxteren, M.; D’Anna, B.; Herrmann, H.; George, C. Photosensitized production of functionalized and unsaturated organic compounds at the air-sea interface. $\underline{S_{c i} \text { Rep }}$. 2015, $5,12741$.
(45) Fu, H.; Ciuraru, R.; Dupart, Y.; Passananti, M.; Tinel, L.; Rossignol, S.; Perrier, S.; Donaldson, D. J.; Chen, J.; George, C. Photosensitized production of atmospherically reactive organic compounds at the air/aqueous interface. L. Am. Chem. Soc. 2015, 137, 8348-8351.

(46) Leermakers, P. A.; Vesley, G. F. The photochemistry of $\alpha$-keto acids and $\alpha$-keto esters. I. Photolysis of pyruvic acid and benzoylformic acid. I. Am. Chem. Soc. 1963, 85, 3776-3779.

(47) Steenken, S.; Sprague, E. D.; Schulte-Frohlinde, D. Photofragmentation of $\alpha$-oxocarboxylic acids in aqueous solution. An EPR study. Formation of semidione radicals by decarboxylative substitution of $\alpha$-oxocarboxylic acids by acyl radicals-I: Glyoxylic, pyruvic, $\alpha$ oxobutyric, $\alpha$-oxoglutaric and $\alpha$-oxoisocaproic acids. Photochem. Photobiol. 1975, 22, 19-27.

(48) Zeldes, H.; Livingston, R. Paramagnetic resonance study of liquids during photolysis. IX. Oxalic acid and its esters. I. Phvs. Chem. 1970, 74, 3336-3346.

(49) Adams, G. E.; Hart, E. J. Radiolysis and photolysis of aqueous formic acid. Carbon monoxide formation. I. Am. Chem. Soc. 1962, 84, 3994-3999.

(50) Flyunt, R.; Schuchmann, M. N.; von Sonntag, C. A common carbanion intermediate in the recombination and proton-catalysed disproportionation of the carboxyl radical anion, $\mathrm{CO}_{2}{ }^{-}$, in aqueous solution. Chem. - Eur. J. 2001, 7, 796-799.

(51) Buxton, G. V.; Sellers, R. M. Acid dissociation constant of the carboxyl radical. Pulse radiolysis studies of aqueous solutions of formic acid and sodium formate. L. Chem. Soc. Faradav Trans. 1 1973, 69, 555-559.

(52) Bothe, E.; Schuchmann, M. N.; Schulte-Frohlinde, D.; von Sonntag, C. Hydroxyl radical-induced oxidation of ethanol in oxygenated aqueous solutions. A pulse radiolysis and product study. Z. Naturforsch., B: J. Chem. Sci. 1983, 38, 212-219.

(53) Vel Leitner, N. K.; Doré, M. Mecanisme d'action des radicaux $\mathrm{OH}$ sur les acides glycolique, glyoxylique, acetique et oxalique en solution aqueuse: Incidence sur la consammation de peroxyde d'hydrogene dans les systemes $\mathrm{H}_{2} \mathrm{O}_{2} / \mathrm{UV}$ et $\mathrm{O}_{3} / \mathrm{H}_{2} \mathrm{O}_{2}$. Water Res. 1997, 31, 1383-1397.

(54) Simic, M.; Neta, P.; Hayon, E. Pulse radiolysis of aliphatic acids in aqueous solutions. II. Hydroxy and polycarboxylic acids. $\underline{\text { L. Phvs. }}$ Chem. 1969, 73, 4214-4219.

(55) Schaefer, T.; van Pinxteren, D.; Herrmann, H. Multiphase chemistry of glyoxal: Revised kinetics of the alkyl radical reaction with molecular oxygen and the reaction of glyoxal with $\mathrm{OH}, \mathrm{NO}_{3}$, and $\mathrm{SO}_{4}{ }^{-}$ in aqueous solution. Environ. Sci. Technol. 2015, 49, 343-350.

(56) Adams, G. E.; Willson, R. L. Pulse radiolysis studies on the oxidation of organic radicals in aqueous solution. Trans. Faradav Soc. 1969, 65, 2981-2987.

(57) Wasa, T.; Musha, S. The polarographic behavior of glyoxal and its related compounds. Bull. Univ. Osaka Prefec. Ser. A 1970, 19, 169180 .

(58) Paul, H.; Fischer, H. Elektronenspinresonanz freier radikale bei photochemischen reaktionen von ketonen in Lösung. Helv. Chim. Acta 1973, 56, 1575-1594.

(59) Epstein, S. A.; Nizkorodov, S. A. A comparison of the chemical sinks of atmospheric organics in the gas and aqueous phase. Atmos. Chem. Phvs. 2012, 12, 8205-8222.

(60) Finlayson-Pitts, B. J.; Pitts, J. Chemistry of the Upper and Lower Atmosphere; Academic Press: San Diego, CA, 1999.

(61) Schöne, L.; Herrmann, H. Kinetic measurements of the reactivity of hydrogen peroxide and ozone towards small atmospherically relevant aldehydes, ketones and organic acids in aqueous solutions. Atmos. Chem. Phys. 2014, 14, 4503-4514. 